\title{
Artificial neural networks (ANN): prediction of sensory measurements from instrumental data
}

Naiara Barbosa CARVALHO ${ }^{1 \star}$, Valéria Paula Rodrigues MINIM ${ }^{1}$, Rita de Cássia dos Santos Navarro SILVA, Suzana Maria DELLA LUCIA², Luis Aantonio MINIM ${ }^{1}$

\begin{abstract}
The objective of this study was to predict by means of Artificial Neural Network (ANN), multilayer perceptrons, the texture attributes of light cheesecurds perceived by trained judges based on instrumental texture measurements. Inputs to the network were the instrumental texture measurements of light cheesecurd (imitative and fundamental parameters). Output variables were the sensory attributes consistency and spreadability. Nine light cheesecurd formulations composed of different combinations of fat and water were evaluated. The measurements obtained by the instrumental and sensory analyses of these formulations constituted the data set used for training and validation of the network. Network training was performed using a back-propagation algorithm. The network architecture selected was composed of 8-3-9-2 neurons in its layers, which quickly and accurately predicted the sensory texture attributes studied, showing a high correlation between the predicted and experimental values for the validation data set and excellent generalization ability, with a validation RMSE of 0.0506 .
\end{abstract}

Keywords: artificial neural network; quantitative descriptive analysis; texture.

\section{Introduction}

Texture properties have been increasingly recognized as important attributes of quality, acceptability, and consumption of foods (SZCZESNIAK, 2002; YATES; DRAKE, 2007; CHILDS; DRAKE, 2009; ROGERS et al., 2010; BARDEN; DRAKE; FOEGEDING, 2012; SILVA et al., 2012a). Sensory descriptive methods have been used to determine which characteristics of cheeses are most desired by consumers and to differentiate types of cheeses in order to segment consumers according to their preferences (MURRAY; DELAHUNTY, 2000; BLEIBAUM et al., 2002; MEILGAARD; CIVILLE; CARR, 2006; CHILDS; DRAKE, 2009; BI; CHUNG, 2011; BARDEN; DRAKE; FOEGEDING, 2012). Although texture is by definition (INTERNATIONAL..., 1981) a sensory property, diverse studies (IRIGOYEN et al., 2002; VAN HEKKEN et al., 2007; DONG, 2009; ROGERS et al., 2010; YANG et al., 2011, SILVA et al., 2012c; VIDIGAL et al., 2012) are found in literature on the use of instrumental techniques for the evaluation of texture.

Sensory texture of a food should be determined by sensory testing as no instrument or combination of instruments can fully replace the human senses. However, because sensory tests are expensive and time consuming, it is desirable to find instrumental measurements capable of predicting sensory measurements, and then routinely use them in industries (LASSOUED et al., 2008). Instrumental measurements may be preferred by the food industry, particularly due to routine quality control since they usually have a lower cost, can perform analyses faster, and are more easily controlled. They also present high data reproducibility, an important characteristic when the measurements must be performed in different industries (WILKINSON; YUKSEL, 1997; SCAMPICCHIO et al., 2006).

However, in order for instrumental measurements to replace sensory attributes, it is essential that they provide accurate predictions. This is achieved by first building a prediction model, based on the calibration of the instrumental measurements with sensory measurements of the same objects (WILKINSON; YUKSEL, 1997).

To model this relationship, traditional regression techniques based on multivariate statistics are typically employed. However, they are based on the linear nature of the variables and do not properly fit to the variables that exhibit nonlinear behavior, a fact commonly observed in data obtained through sensory tests (JOHNSON; WICHERN, 1998; DELLA LUCIA; MINIM, 2010).

Accordingly, one of the most promising alternatives to overcome this limitation is the application of artificial neural networks (ANN) since they are computational techniques well adapted to non-linear data (CHEN, 1991; NUI et al., 1991; DELLA LUCIA; MINIM, 2010). The ANN's are composed of processing elements (nodes) or artificial neurons, arranged in a parallel, highly interconnected structure, which process information by means of forward dynamic responses to external stimuli (BAUGHMAN; LIU, 1995; HAYKIN, 2002). Such networks are based on the operation of the human brain, particularly its neurons; artificial units of the networks are interconnected by artificial synapses associated with weights (symbolized by an array of numbers) which store knowledge acquired by the network and can be adjusted by a learning

${ }^{1}$ Departamento de Tecnologia de Alimentos, Universidade Federal de Viçosa - UFV, Campus Universitário, CEP 36570-000, Viçosa, MG, Brazil, e-mail: naiara.carvalho@ufv.br

${ }^{2}$ Departamento de Engenharia de Alimentos, Centro de Ciências Agrárias, Universidade Federal do Espírito Santo - UFES, Alto Universitário, CP 16, CEP 29500-000, Alegre, ES, Brazil

${ }^{*}$ Corresponding author 
process (BAUGHMAN; LIU, 1995; ZURADA, 1995; BRAGA; CARVALHO; LUDEMIR, 2000; HAYKIN, 2002).

In the feed-forward multi-layer perceptrons considered in this paper, the nodes are arranged in several layers: an input layer containing one node for each independent variable, one or more hidden layers where the data are processed, and an output layer, containing one node for each dependent variable. The most widely used algorithm for weight adjustment is currently the error back propagation algorithm. This algorithm determines the contribution of each weight on the prediction error, according to the chain rule of differentiation, and adjusts the weight by a fixed proportion of that contribution. The back propagation algorithm, when used in combination with continuous nonlinear transfer functions such as the sigmoidal or logistic functions, has proven successful in a wide range of applications (HAYKIN, 2002; KUPONGSAK et al., 2004).

In the field of Sensory Analysis of Foods, specifically with respect to the study of the relationship between sensory and instrumental measurements, it is observed that are few studies addressing the application of ANNs. Thai and Shewfelt (1991) used an ANN for modeling the sensory quality of the color of peaches and tomatoes by means of mathematical relationships linking human sensory evaluations to physical measurements of color of these foods. Bardot et al. (1994) studied the correlation between sensory and instrumental data in the prediction of drink flavor from its chemical composition. Angerosa et al. (1996) applied this modeling tool to establish the correlation between sensory and instrumental data of olive oil. Boccorh and Paterson (2002), in order to rationalize the use of currant concentrate in beverage production from this fruit, produced an ANN model to predict the flavor intensity of currant concentrates from gas chromatography data. Dong (2009) applied back propagation neural network for evaluating sensory texture properties of cooked sausage.

Therefore, the objective of the present study was to predict sensory measurements from instrumental texture measurements of light cheesecurds by modeling with ANNs, seeking to obtain fast and accurate information on the texture attributes perceived by trained judges.

\section{Materials and methods}

\subsection{Experimental data}

\section{Samples}

Sensory and instrumental measurements (Texture Profile Analysis, rotational and oscillatory tests) were used for the development of the ANN structure of nine formulations of light cheesecurds supplemented with whey protein concentrate (WPC) containing different concentrations of fat (F) and water (W). The composition of the different formulations was defined by the Central Composite Rotatable Design (CCRD) with two factors (fat and water) at two levels $\left(2^{2}\right)$, four axial points $(2 \times 2)$, and the central point (CP). The $\mathrm{CP}$ was repeated two times for a total of 11 tests (Table 1 ).
Table 1. Combinations of fat and water contents with their respective codes.

\begin{tabular}{ccccc}
\hline Formulations & Fat $(\%)$ & Codes $\left(\mathrm{x}_{1}\right)$ & Water $(\%)$ & Codes $\left(\mathrm{x}_{2}\right)$ \\
\hline F1 & 17.3 & 1 & 65 & -1 \\
F2 & 17.3 & 1 & 70 & 1 \\
F3 & 10.2 & -1 & 70 & 1 \\
F4 & 10.2 & -1 & 65 & -1 \\
F5 & 13.7 & 0 & 71 & $\sqrt{ } 2$ \\
F6 & 18.7 & $\sqrt{ } 2$ & 67.5 & 0 \\
F7 & 13.7 & 0 & 64 & $-\sqrt{ } 2$ \\
F8 & 8.7 & $-\sqrt{ } 2$ & 65 & -1 \\
F9 * & 13.7 & 0 & 67.5 & 0 \\
\hline
\end{tabular}

* average central point.

The light cheesecurd samples were processed utilizing the mass obtained by direct acidification of milk with lactic acid $85 \%$ PA at $70^{\circ} \mathrm{C}$, according to the technology described by Alves et al. (2007), in an open pan with mechanical agitation at $50 \mathrm{rpm}$. The addition of ingredients to the different formulations was controlled by a mass balance so that only the total fat and water contents varied. All samples were stored under refrigeration $\left(7 \pm 1{ }^{\circ} \mathrm{C}\right)$ until analysis.

\section{Characterization of the product}

Instrumental analysis - The instrumental texture evaluation of the light cheesecurds was performed by means of imitative (Texture Profile) and fundamental tests (rotational and oscillatory tests) at $10{ }^{\circ} \mathrm{C}$. In the texture profile analysis (TPA), parameters of firmness, chewiness, gumminess, cohesiveness, and elasticity were obtained from the force $\times$ time curves generated during the test by the Blue Hill 2.0 software (Instron, United States, 2005), according to the method described in Gallina et al. (2008). Rotational and oscillatory tests were carried out in an rotational rheometer (HAAKE MARS, Thermo Electron Corp.,Germany) equipped with a water bath (Phoenix 2C30P, Thermo Electron Corp., Germany), using a serrated parallel plates system PP 20S DIN (20 mm diameter) with a gap size set to $1 \mathrm{~mm}$ for all formulations. Rotational and oscillatory parameters assays were performed determining the parameters of yield stress $\left(\tau_{\mathrm{o}}\right)$, apparent viscosity $\left(\eta_{\mathrm{ap}, 10}\right)$, and the elastic $\left(G^{\prime}\right)$ and viscous component $\left(G^{\prime \prime}\right)$. The tangent $\delta\left(G^{\prime \prime} / G^{\prime}\right)$ was calculated at the frequency of $4.64 \mathrm{~Hz}$.

Descriptive Analysis - Sensory characteristics of the formulations was performed using the conventional profile (Quantitative Descriptive Analysis), as described by Silva et al. (2012b). Intensities of the sensory attributes consistency and spreadability were evaluated by nine trained judges using the unstructured scale anchored by the terms weak (0) and strong (9), Table 2 . The attributes consistency and spreadability were evaluated using a plastic spoon (visual evaluation). To evaluate the spreadability of the samples a saltine cracker was used. Refrigerated samples $\left(10^{\circ} \mathrm{C}\right)$ were presented to the panelists at room temperature $\left(25^{\circ} \mathrm{C}\right)$. 
Table 2. Sensory texture attributes evaluated by the trained judges and their respective definitions.

\begin{tabular}{cc}
\hline Attributes & Definitions \\
\hline Consistency & $\begin{array}{c}\text { Force necessary to spread the product with a spoon. } \\
\text { Ability to spread the cheesecurd on a cracker with } \\
\text { a spoon. }\end{array}$ \\
\hline
\end{tabular}

\subsection{Modeling using artificial neural networks}

In order to model the sensory-instrumental relationship of light cheesecurds, the ANN technique was applied to estimate sensory attribute measurements (consistency and spreadability) as a function of instrumental measurements (firmness, gumminess, chewiness, elasticity, cohesiveness, yield stress, apparent viscosity, and tangent $\delta$ ). Therefore, the network built consisted of eight processing elements in the input layer and two processing elements in the output layer.

The back-propagation algorithm was used for the prediction of sensory attributes employed for supervised training of networks applying the Extended Delta-Bar-Delta rule (MINAI; WILLIAMS, 1990) that utilizes a heuristic for varying the learning rate and the time coefficient during training, which begins with values of 0.3 and 0.4 , respectively (NEURALWARE, 2001); the activation function used was the sigmoid type. The network was developed using the commercial software NeuralWorks Professional II/ Plus (Neuralware Inc., Pittsburg, PA, USA).

Initially, a set of 99 data points was obtained. A visual assessment of data dispersion showed that individual scores of some judges were quite distant from those of the other team and were therefore removed (LUNDAHL; McDANIEL, 1988, 1990). A final set of 72 data points was divided into two sub-sets used for training and validation of the ANN.

The validation set was defined randomly and consisted of data referring to the formulations F2, F3 and F4, and the remaining data made up the training set. Thus, $70 \%$ of the data were used for training and 30\% for the validation phase.

The criterion for selecting the best network and determining the number of iterations for training the network is the lowest value of the square root of the mean squared error (RMSE - root mean square error) (Equation 1), later referred to only as error (RMSE) of the data set validation:

$$
\text { RMSE }=\sqrt{\frac{1}{n} \sum_{i=1}^{n}\left(x_{d}-x_{p}\right)^{2}}
$$

where $n$ is the number of data pairs and $x_{\mathrm{d}}$ and $x_{\mathrm{p}}$ are the experimental (also called desired values) and predicted values of the sensory attributes, respectively.

The RMSE of the training and validation steps, as well as the correlation coefficients $(r)$ and analysis of the scatter plot of residues between the experimental and predicted values for the selected network were used as a measurement of its performance.

\subsection{Ethics committee}

This research project was analyzed and approved by the Scientific Committee of the Postgraduate Department of Food Technology - Federal University of Viçosa, process n. 50717260672/2011, meeting, as outlined, the necessary requirements for its publication.

\section{Results and discussion}

\subsection{Training the neural network}

In order to improve the performance of the ANN, the original scores of the sensory attributes evaluated by the trained judges were transformed for variance reduction. Data transformation was performed using the mean and variance of the scores of sensory attributes assigned to the nine formulations of the light cheesecurds by the trained judges (NAYAK; DWIVEDI; SRIVASTAVA, 1993; SRIVASTAVA, 2003; KRISHNAMURTHY et al., 2007). According to this method, if the variance $\left(V_{\mathrm{ij}}\right)$ of the scores of the $\mathrm{i}^{\text {th }}$ attribute for the $\mathrm{j}^{\text {th }}$ formulation is greater than one, the data are transformed according to Equation 2:

$$
T_{i j k}=\frac{\left(X_{i j k}-\bar{X}_{i j}\right)}{V_{i j}}+\bar{X}_{i j}
$$

where $X_{\mathrm{ijk}}$ is the score of the $\mathrm{i}^{\text {th }}$ attribute for the $\mathrm{j}^{\text {th }}$ formulation attributed by the $\mathrm{k}^{\text {th }}$ judge, $\bar{X}_{\mathrm{ij}}$ is the average score of the $\mathrm{i}^{\text {th }}$ attribute for the $\mathrm{j}^{\text {th }}$ formulation, and $\mathrm{T}_{\mathrm{i} \mathrm{j} \mathrm{k}}$ is the transformed score of the $i^{\text {th }}$ attribute for the $j^{\text {th }}$ formulation attributed by the $\mathrm{k}^{\text {th }}$ judge.

When $V_{\mathrm{ij}}$ is less than one, the following transformation method can be used (Equation 3):

$T_{i j k}=\left(X_{i j k}-\bar{X}_{i j}\right) * V_{i j}+\bar{X}_{i j}$

Figure 1 shows the dispersion of original and transformed scores for the two sensory attributes evaluated. It is observed that there was a considerable reduction in the dispersion of data after transformation. This result was also confirmed by Krishnamurthy et al. (2007), when applying this transformation to reduce the variance of scores for the nine sensory attributes of ten different types of meat broth assessed by a trained team.

\subsection{Selecting the best architecture of the network prediction}

In order to determine the ANN configuration for the prediction of sensory measurements, the number of neurons in the first and second hidden layers varied from three to fifteen fixing the number of iterations and the division of the training and validation data sets and two hidden layers were tested.

Among various architectures tested that showed the minimum RMSE of the validation data was the architecture composed of two hidden layers with three neurons in the first hidden layer and nine in second hidden layer, and therefore this ANN configuration was selected for the present study (Figure 2). 

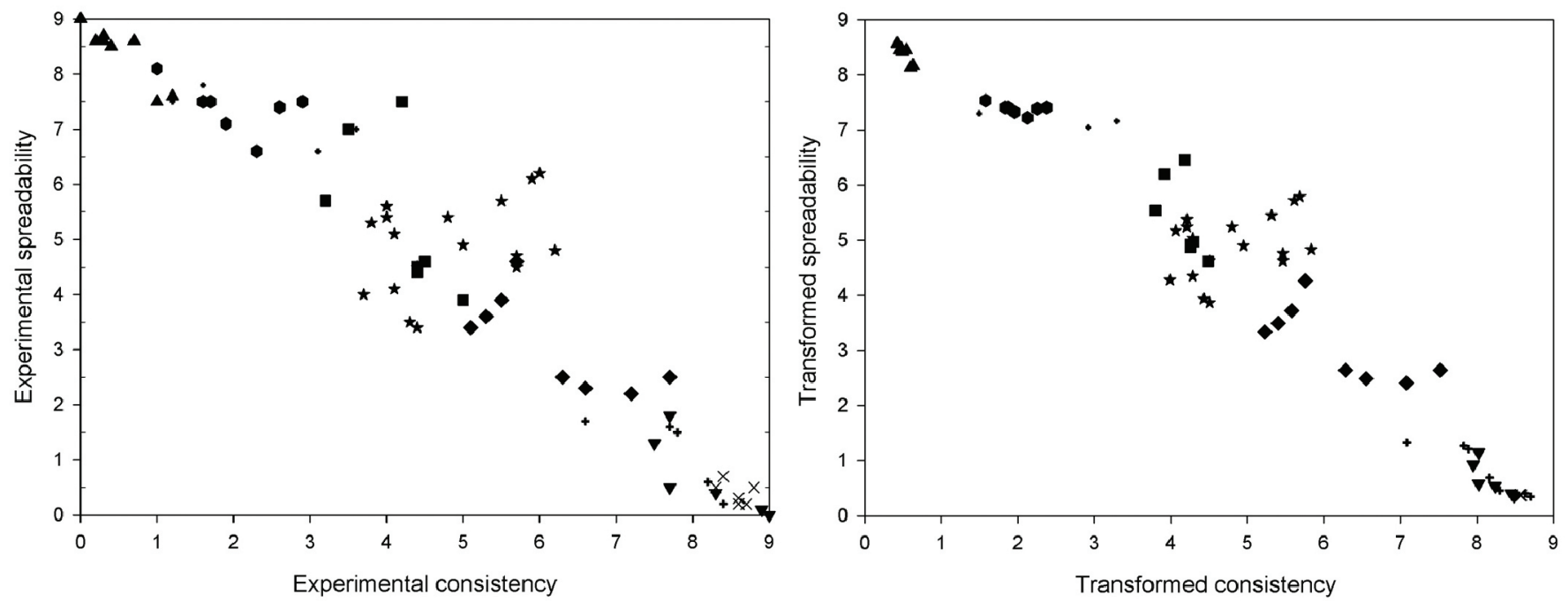

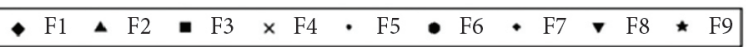

Figure 1. Dispersion of original and transformed scores for the attributes of consistency and spreadability of light cheesecurds.

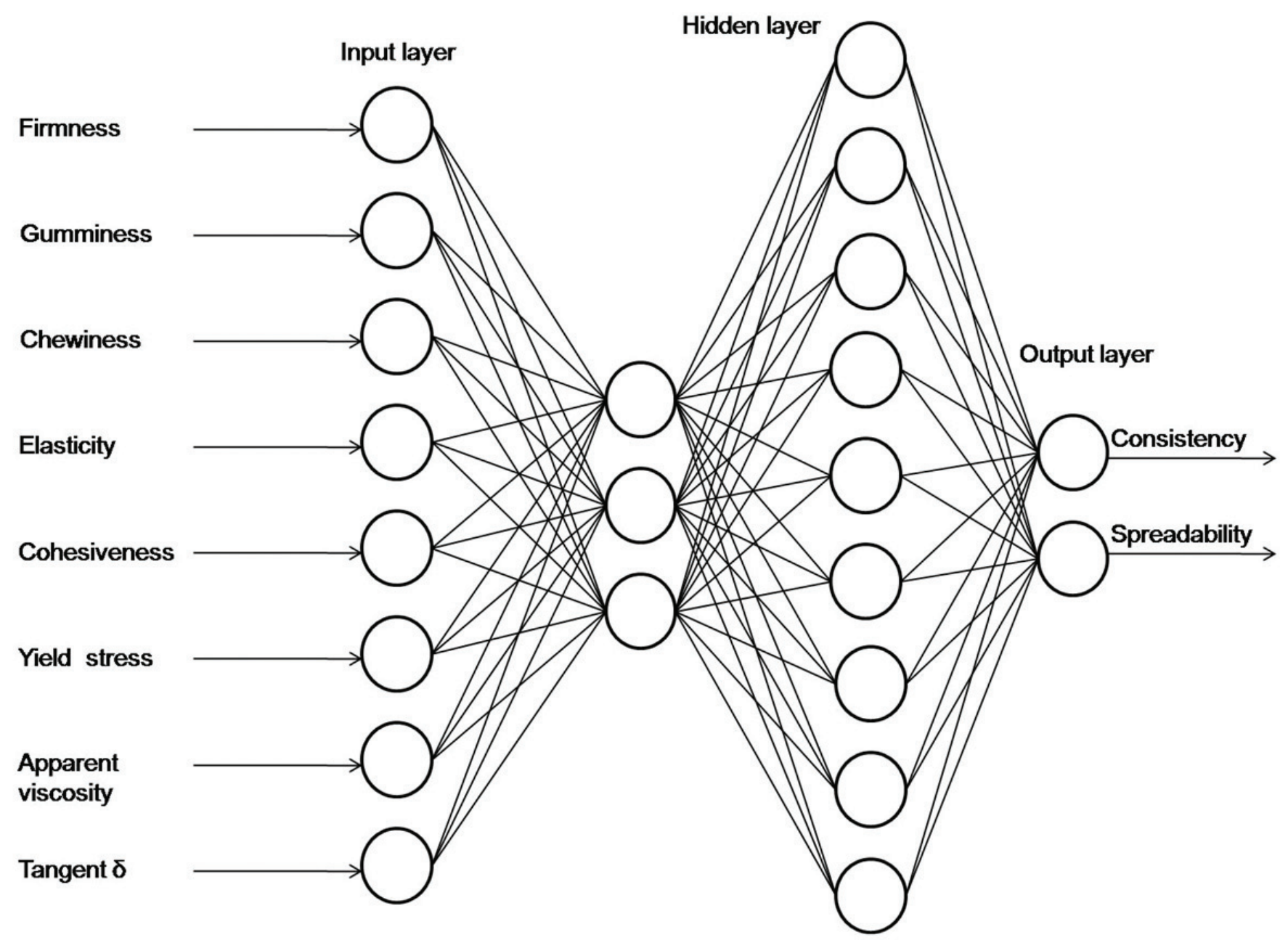

Figure 2. Architecture of ANN selected for prediction of sensory attributes of consistency and spreadability. 


\subsection{Selection of the best number of iterations}

To get good performance from the ANN, it is essential to monitor the learning progress as a way to detect when a neural network is improperly trained, resulting in predictions with high RMSE or when it is excessively trained in order to memorize rather than generalize responses.

In the present study, in order to select the number of iterations for adequate training of the network, a network with 8-3-9-2 neurons in its layers was used, and data sets were divided as specified in Section 2.2 of the Materials and Methods. Thus, the network was trained for a large number of iterations, up to $1,000,000$ epochs.

The RMSE of the training and validation data sets was determined simultaneously and at frequent intervals. It can be observed in Figure 3 that initially the RMSE decreases for both the training and the validation data sets after reaching a certain minimum; the error in the validation set begins to increase while the error of the training set continues to decrease to remain constant, and when the validation error begins to increase, the training of the network should be stopped. Thus, it appears that the number of iterations to properly train the network is 4,000 epochs. This is an important step since memorization of the network can be avoided.

\subsection{Performance of the selected ANN}

The RMSE values which characterize the performance of the selected network indicate that the network was properly trained since it exhibited a low error (0.0485) for the training phase, and it also showed good generalization capacity, considering the low value of the RMSE (0.0506) for the validation data set.

Figure 4 shows the graph of residues for the sensory attributes consistency and spreadability predicted by the ANN for the complete data set of available points, i.e., for the data set used for training and for the data set used for validation. The data listed from 1 to 50 correspond to the examples provided for the training of the network, and those from 51 to 72 are the

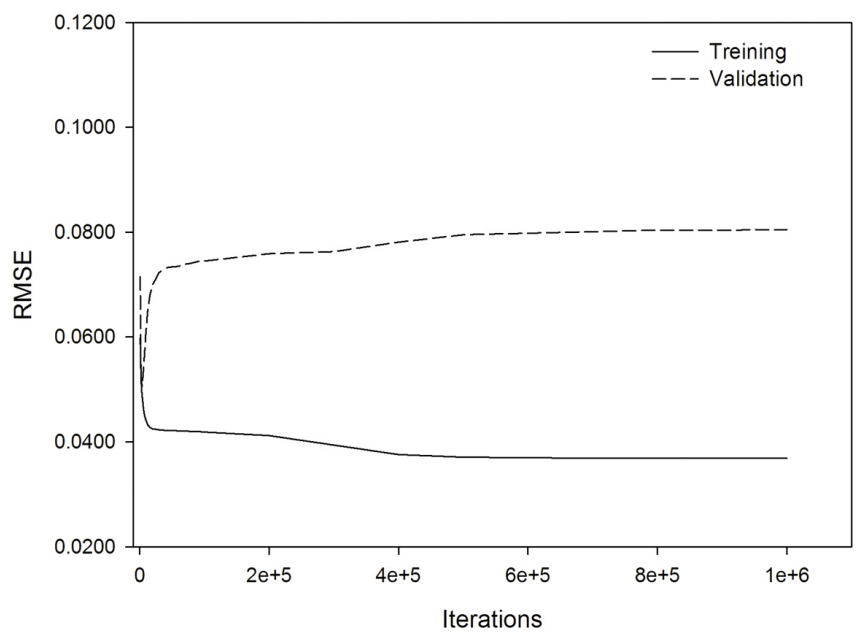

Figure 3. Effect of the number of iterations on the RMSE of the training and validation data sets. data used for validation. It should be noted that the distribution of residues occurs randomly around the $\mathrm{x}$-axis, showing no bias variation in the responses of the model.

Comparisons between the experimental and predicted values by the ANN for the validation data set are shown in Figure 5. It is observed that the experimental and predicted values for the attributes consistency and spreadability were highly correlated $(r>0.9000)$. Such correlations were also significant $(\mathrm{p}<0.0001)$ by the $\mathrm{F}$ test, indicating a good agreement between these values and a good fit of the neural model to the behavioral relationship between the sensory and instrumental measurements.

The results obtained for the predicted values of the two attributes in question were considered excellent since they predicted the same scores of sensory attributes determined by means of a Quantitative Descriptive Analysis (QDA), and in this case it is determined whether there was an agreement between the rating scores of the judges with limited accuracy due to the

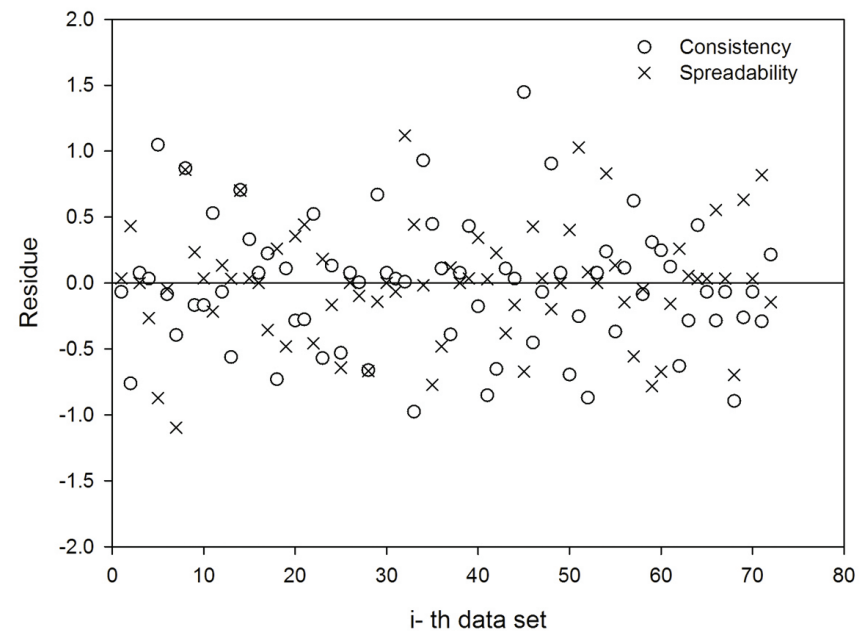

Figure 4. Residues for the measures of consistency and spreadability predicted by the ANN for training and validation data sets.

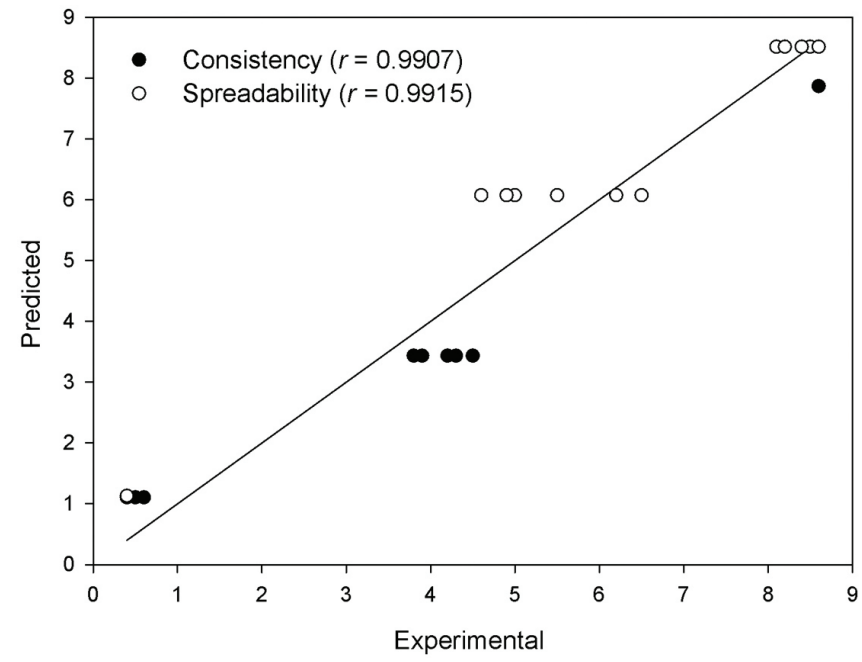

Figure 5. Comparison between the experimental and predicted values by the selected ANN for the consistency and spreadability attributes. 

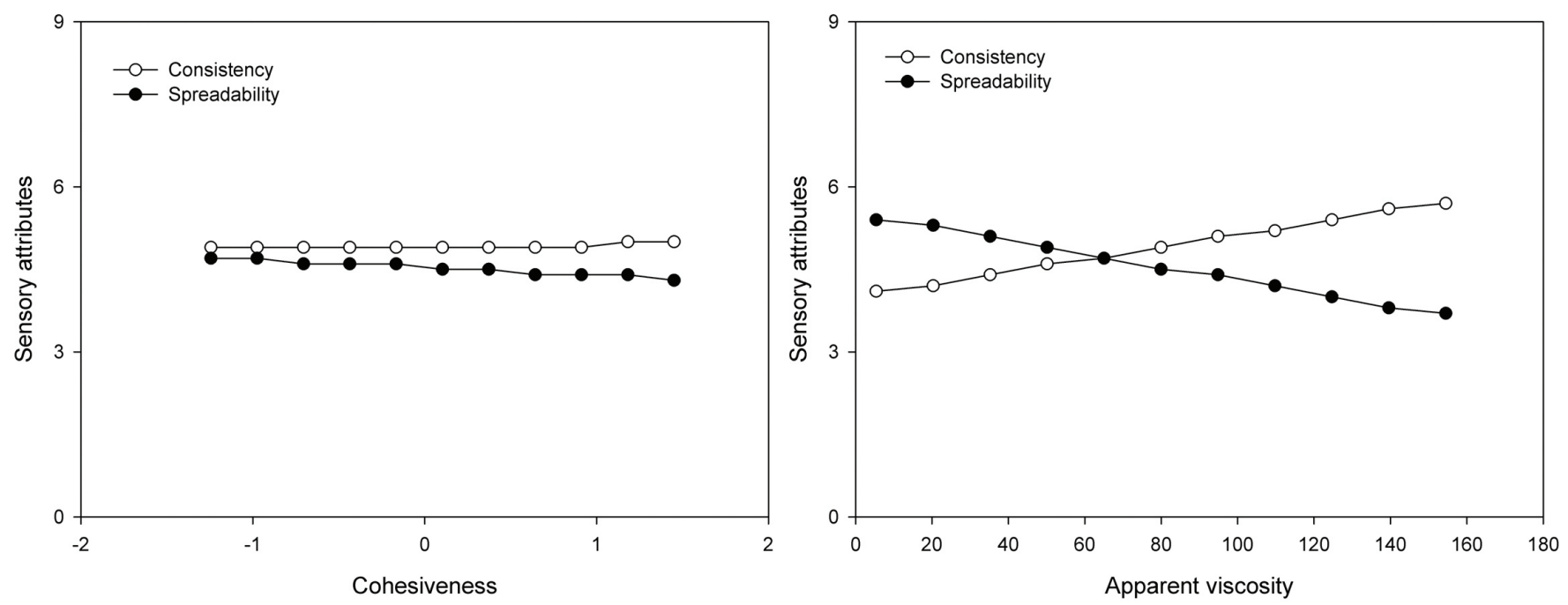

Figure 6. Influence of cohesivenss and apparent viscosity on the sensory attributes studied.

lack of pre-determined QDA values. It is important that, for the same formulation, the sensory panel attributed scores similar to those that were evaluated, which describes the same intensity.

This fact indicates that the developed model showed good performance since the predicted values, for the hidden data during training of the ANN, were accurate, and although they exhibited errors in relation to the experimental value of the attributes, these errors are not significant in terms of the sensory analysis. This is because the scores obtained by prediction maintain the same range of intensity as the experimental data which characterize the light cheesecurd with respect to its texture attributes evaluated.

A sensitivity analysis was performed with the ANN model in order to evaluate the variables that most influenced the consistency and spreadability of the light cheesecurd formulations, in which it was determined that the input variables of viscosity and cohesiveness were those of the greatest relative importance.

It was observed in Figure 6 that as cohesiveness increased, the spreadability of the light cheesecurds decreased and consistency increased. These variations are small because the range studied is small. However, this variability is of great importance for the prediction of output data since even a small interval can cause changes in sensory attributes.

With respect to the behavior of apparent viscosity, it was observed (Figure 6) that as this parameter increased, the consistency of the light cheesecurds also increased and its spreadability decreased, both with large variations in the unstructured nine-point scale. This indicates that variations in this variable change the sensory characterization of light cheesecurds since for low values of apparent viscosity the light cheesecurds show lower consistency and higher spreadability, which characterizes a softer product. For intermediate values of apparent viscosity, the products were obtained with intermediate consistency and spreadability (close to 4.5 in the unstructured nine-point scale). For high values of this variable, consistency increased and spreadability decreased, characterizing a more firm cheesecurd formulations. Therefore, although it was verified that cohesiveness and apparent viscosity caused major changes in the output variables. Figure 6 shows that by varying only the apparent viscosity of the formulations and maintaining all other independent variables constant, it is possible to obtain accurate information on the behavior of cohesiveness and spreadability of the light cheesecurds studied.

A similar result was found by Angerosa et al. (1996), who observed a significant correlation between the predicted and experimental values $\left(\mathrm{R}^{2}=0.874, \mathrm{p}=0.05\right)$ of the scores attributed by the trained judges who evaluated the sensory quality of virgin olive oil from gas chromatography data employing the ANN technique to model the relationship between sensory and instrumental measurements.

Boccorh and Paterson (2002) also found a good correlation $(0.68 \leq \mathrm{r} \leq 0.89)$ between gas chromatography data (instrumental measurement) and the flavor intensity of concentrated blackcurrant beverages by modeling applying ANN.

\section{Conclusion}

The selected and trained multilayer perceptron network enabled highly accurate prediction of the measurements of the sensory attributes studied. The network configuration with 8-39-2 neurons in its layers was the one that best fit to the problem investigated, showing great ability for generalization, with a validation RMSE of 0.0506 and high correlation $(r>0.9000)$ between the predicted and experimental values data for the validation data set.

It appears that the ANN technique showed great potential for modeling the relationship between sensory and instrumental measurements with advantages such as accuracy and simplicity, and it can also provide accurate and rapid responses to new information that were not previously detected during its training. 
Thus, it was found that the final prediction model of the instrumental sensory measurements, obtained by means of this modeling tool, can be a promising alternative for industrial applications and can quickly and inexpensively predict the same result obtained by a trained team.

\section{Acknowledgements}

The authors would like to acknowledge the financial support provided by CNPq, CAPES, and FAPEMIG.

\section{References}

ALVES, R. M. V. et al. Effect of light and packages on stability of spreadable processed cheese. International Dairy Journal, v. 17, n. 4, p. 365-373, 2007. http://dx.doi.org/10.1016/j.idairyj.2006.04.004

ANGEROSA, F. et al. Sensory evaluation of virgin olive oils by artificial neural network processing of dynamic headspace gas chromatographic data. Journal of the Science of Food and Agriculture, v. 72, n. 3, p. 323-328, 1996. http://dx.doi.org/10.1002/ (SICI)1097-0010(199611)72:3<323::AID-JSFA662>3.0.CO;2-A

BARDEN, L. M.; DRAKE, M. A.; FOEGEDING, E. A. Impact of sample thickness on descriptive texture analysis of cheddar cheese. Journal of Sensory Studies, v. 27, p. 286-293, 2012. http://dx.doi. org/10.1111/j.1745-459X.2012.00392.x

BARDOT, I. et al. Sensory-instrumental correlations by combining data analysis and neural network techniques. Food Quality and Preference, v. 5, n. 1-2, p. 159-166, 1994. http://dx.doi. org/10.1016/0950-3293(94)90023-X

BAUGHMAN, D. R.; LIU, Y. A. Neural networks in bioprocessing and chemical engineering. San Diego: Academic Press, 1995. 488 p.

BI, J.; CHUNG, J. Identification of drivers of overall liking - Determination of relative importances of regressor variables. Journal of Sensory Studies, v. 26, p. 245-254, 2011. http://dx.doi.org/10.1111/j.1745459X.2011.00340.X

BLEIBAUM, R. N. et al. Comparison of sensory and consumer results with electronic nose and tongue sensors for apple juices. Food Quality and Preference, v. 13, n. 6, p. 409-422, 2002. http://dx.doi. org/10.1016/S0950-3293(02)00017-4

BOCCORH, R. K., PATERSON, A. An artificial neural network model for predicting flavour intensity in blackcurrant concentrates. Food Quality and Preference, v. 13, n. 2, p. 117-128, 2002. http://dx.doi. org/10.1016/S0950-3293(01)00072-6

BRAGA, A. P.; CARVALHO, A. P. L. F.; LUDEMIR, T. B. Redes neurais artificiais:teoria e aplicações. Rio de Janeiro: LTC, 2000. 262 p.

CHEN, C. H. On the relationships between statistical pattern recognition and artificial neural Networks. International. Journal of Pattern Recognition and Artificial Intelligence, v. 5, p. 655-661, 1991. http://dx.doi.org/10.1142/S0218001491000387

CHILDS, J. L.; DRAKE, M. Consumer perception of fat reduction in cheese. Journal of Sensory Studies, v. 24, p. 902-921, 2009. http:// dx.doi.org/10.1111/j.1745-459X.2009.00243.x

DELLA LUCIA, S. M.; MINIM, L. A. Redes neurais artificiais: fundamentos e aplicações. In: MINIM, V. P. R. (Ed.). Análise sensorial: estudos com consumidores. Viçosa: Editora UFV, 2010. cap. 9, p. 258-279.

DONG, Q. Bp neural network for evaluating sensory texture properties of cooked sausage. Journal of Sensory Studies, v. 24, p. 833-850, 2009. http://dx.doi.org/10.1111/j.1745-459X.2009.00240.x
GALLINA, D. A. et al. Influence of storage temperature on the texture profile and colour characteristics of UHT Requeijão cremoso. Brazilian Journal of Food Technology, v. 11, n. 3, p. 169-174, 2008.

HAYKIN, S. Redes neurais: princípios e prática. 2. ed. Porto Alegre: Bookman, 2002. 900 p.

IRIGOYEN, A. et al. Sensory and instrumental evaluations of texture in cheeses made from ovine milks with differing fat contents. Journal of Sensory Studies, v. 17, p. 145-161, 2002. http://dx.doi. org/10.1111/j.1745-459X.2002.tb00339.x

I N T E R N A T I O N A L O R G A N I Z A T I O N F O R STANDARDIZATION - ISO. Sensory analysis vocabulary. Geneva: International Organization for Standardization, 1981. part 4.

JOHNSON, R. A.; WICHERN, D. W. Applied multivariate statistical analysis. 4. ed. Upper Saddle River: Prentice-Hall, 1998. 816 p.

KRISHNAMURTHY, R. et al. Prediction of consumer liking from trained sensory panel information: Evaluation of neural networks. Food Quality and Preference, v. 18, n. 2, p. 275-285, 2007. http:// dx.doi.org/10.1016/j.foodqual.2006.01.001

KUPONGSAK, S. et al. Set point determination from sensory evaluations for food process control. Journal of Food Process Engineering, v. 27, n. 2, p. 87-102, 2004. http://dx.doi. org/10.1111/j.1745-4530.2004.tb00624.x

LASSOUED, N. et al. Baked product texture: correlations between instrumental and sensory characterization using Flash Profile. Journal of Cereal Science, v. 48, n. 1, p. 133-143, 2008. http://dx.doi. org/10.1016/j.jcs.2007.08.014

LUNDAHL, D. S.; McDANIEL, M. R. The panelist effect-fixed or random. Journal of Sensory Studies, v. 3, n. 2, p. 113-121, 1988. http://dx.doi.org/10.1111/j.1745-459X.1988.tb00434.x

LUNDAHL, D. S.; McDANIEL, M. R. Use of contrasts for the evaluation of panel inconsistency. Journal of Sensory Studies, v. 5, n. 4, p. $265-$ 277, 1990. http://dx.doi.org/10.1111/j.1745-459X.1990.tb00496.x

MEILGAARD, M. C.; CIVILLE, G. V.; CARR, B. T. Sensory evaluation techniques, 4. ed. Boca Raton: CRC, 2006.

MINAI, A. A.; WILLIAMS, R. D. Acceleration of back-propagation through learning rate and momentum adaptation. International Joint Conference on Neural Networks, v. 1, p. 676-679, 1990.

MURRAY, J. M.; DELAHUNTY, C. M. Selection of standards to reference terms in a Cheddar cheese flavor language. Journal of Sensory Studies, v. 15, n. 2, p. 179-199, 2000. http://dx.doi. org/10.1111/j.1745-459X.2000.tb00264.x

NAYAK, M. S.; DWIVEDI, R.; SRIVASTAVA, S. K. Transformed cluster analysis: An approach to the identification of gases/odours using an integrated gas-sensor array. Sensors and Actuators B: Chemical, v. 12 , n. 1, p. 103-110, 1993. http://dx.doi.org/10.1016/09254005(93)80005-V

NEURALWARE. Neural computing: a technology handbook for NeuralWorks Professional II / Plus. USA: Neuralware, 2001. 325p.

NUI, A. et al. A comparative study of model fitting by using neural networks and regression. Proceedings of SPIE-International Society of Optical Engineering, v. 1469, p. 495-505, 1991.

ROGERS, N. R. et al. Rheological properties and microstructure of Cheddar cheese made with different fat contents. Journal of Dairy Science, v. 93, n. 10, p. 4565-4576, 2010. PMid:20854990. http:// dx.doi.org/10.3168/jds.2010-3494

SCAMPICCHIO, M. et al. Amperometric electronic tongue for the evaluation of the tea astringency. Electroanalysis, v. 18, n. 17, p. 1643-1648, 2006. http://dx.doi.org/10.1002/elan.200603586 
SILVA, R. C. S. N. et al. Otimização da aceitabilidade sensorial de requeijão cremoso light. Ciência Rural, v. 42, p. 360-366, 2012a.

SILVA, R. C. S. N. et al. Optimized Descriptive Profile: a rapid methodology for sensory description. Food Quality and Preference, v. 24, n. 1, p. 190-200, 2012b.

SILVA, R. C. S. N. et al. Sensory and Instrumental Consistency of Processed Cheeses. Journal of Food Research, v. 1, p. 204-213, 2012c. http://dx.doi.org/10.5539/jfr.v1n3p204

SZCZESNIAK, A. S. Texture is a sensory property. Food Quality and Preference, v. 13, n. 4, p. 215-225, 2002. http://dx.doi.org/10.1016/ S0950-3293(01)00039-8

SRIVASTAVA, A. K. Detection of volatile organic compounds (VOCs) using $\mathrm{SnO}_{2}$ gas sensor array and artificial neural network. Sensors and Actuators B: Chemical, v. 96, n. 1-2, p. 24-37, 2003. http:// dx.doi.org/10.1016/S0925-4005(03)00477-5

THAI, C. N.; SHEWFELT, R. L. Modelling sensory colour quality of tomato and peach: Neural networks and statistical regression. American Society of Agricultural Engineering, v. 34, n. 3, p. 950 955, 1991. http://dx.doi.org/10.13031/2013.31754

VAN HEKKEN, D. L. et al. Rheology and melt characterization of lowfat and full fat Mozzarella cheese made from microfluidized milk.
LWT-Food Science and Technology. v. 40, p. 89-98, 2007. http:// dx.doi.org/10.1016/j.lwt.2005.08.005

VIDIGAL, M. C. T. R. et al. Effect of whey protein concentrate on texture of fat-free desserts: sensory and instrumental measurements. Ciência e Tecnologia de Alimentos, v. 32, p. 412-418, 2012. http:// dx.doi.org/10.1590/S0101-20612012005000047

WILKINSON, C.; YUKSEL, D. Using artificial neural networks to develop prediction models for sensory-instrumental relationships; an overview. Food Quality and Preference, v. 8, n. 5-6, p. 439-445, 1997. http://dx.doi.org/10.1016/S0950-3293(97)00016-5

YANG, X. et al. Modeling the rheological properties of cheddar cheese with different fat contents atvarious temperatures. Journal of Texture Studies, v. 42, p. 331-348, 2011. http://dx.doi.org/10.1111/ j.1745-4603.2011.00283.x

YATES, M. D.; DRAKE, M. A. Texture properties of Gouda cheese. Journal of Sensory Studies, v. 22, p. 493-506, 2007. http://dx.doi. org/10.1111/j.1745-459X.2007.00124.x

ZURADA, J. M. Multilayer feedforward networks. In: ZURADA, J. M. Introduction to Artificial Neural System. St. Paul: West Publishing Company, 1995. p. 163-235. 